\section{Cerebral stroke in a teenage girl with paroxysmal nocturnal hemoglobinuria} Antonino Trizzino, ${ }^{2}$ Fabrizia Ferraro, ${ }^{2}$ Delia Russo, ${ }^{2}$ Giuseppe Santangelo, ${ }^{3}$ Francesca Cardella, ${ }^{4}$ Angela Trizzino, ${ }^{2}$ Floriana Di Marco, ${ }^{2}$ Piero Farruggia ${ }^{2}$

${ }^{1}$ Specialistic Oncology Laboratory Unit, ${ }^{2}$ Pediatric Hematology and Oncology Unit, Oncology Department, ${ }^{3}$ Pediatric Neurology and Psychiatric Unit, ${ }^{4}$ Department of Pediatrics, ARNAS Hospitals Civico, Di Cristina e Benfratelli, Palermo, Italy

\begin{abstract}
We report a case of paroxysmal nocturnal hemoglobinuria (PNH) in a 14 year-old girl presenting a cerebral arterial thrombosis. The initial diagnosis was carential anemia due to menarche following identification of slight macrocytic anemia, leucopenia and mild thrombocytopenia at routine blood analysis. The child was eventually referred to a children's hospital after the onset of progressive fatigue, anorexia and paleness. Severe anemia (hemoglobin 6 $\mathrm{g} / \mathrm{dL}$ ) with negative Coombs test, mild leucopenia (white blood cells $4.9 \times 10^{9} / \mathrm{L}$ ) and thrombocytopenia (platelets $97 \times 10^{9} / \mathrm{L}$ ) and high values of lactate dehydrogenase $(2855$ $\mathrm{U} / \mathrm{L}$ ) were identified; a packed red cells transfusion was administered. Her condition worsened and she subsequently presented complete right hemiplegia, aphasia and coma; magnetic resonance imaging revealed a massive ischemic lesion. A diagnosis of PNH was eventually made following high sensitivity flow cytometry, which identified a PNH clone (CD66b negative equal to $93.7 \%$ of granulocytes). Fast recovery from neurologic and hematological problems occurred in response to anticoagulant therapy and intravenous therapy with eculizumab. We are convinced that PNH should be included in the differential diagnosis of children presenting with cytopenia.
\end{abstract}

\section{Introduction}

Paroxysmal nocturnal hemoglobinuria (PNH) is an uncommon acquired, as distinct from inherited, genetic disease characterized by complement-mediated hemolysis and clone expansion of affected cells of various hematopoietic lineages that are thought to be derived from an abnormal multipotent hematopoietic stem cell. The mutation is somatic and occurs in the X-linked PIG-A gene encoding for glycosylphosphatidylinositol (GPI)-protein, required for the biosynthesis of glycosylphosphatidylinositol anchor, that attaches dozens of proteins to the cell surface. ${ }^{1-4}$

The GPI anchor is deficient in the affected cells from patients with $\mathrm{PNH}$, leading to the lack of surface expression of multiple GPI-anchored proteins, such as decayaccelerated factor CD55 and CD59, both of which play roles in the protection of red cells from the action of complement. ${ }^{5,6}$ Free hemoglobin released from intravascular hemolysis leads to circulating nitrous oxide depletion and contributes to many of the clinical manifestations of $\mathrm{PNH}$, including fatigue, erectile dysfunction, esophageal spasm, and thrombosis.?

The condition is extremely rare in children, where it is often misdiagnosed, and it is more likely to occur in teenagers than in younger children. ${ }^{8-12}$ Thromboses are very severe complications of the disease, frequently occurring in unusual sites such as the skin, liver, spleen portal circle, and affecting 29 to $44 \%$ of patients. ${ }^{13}$ However, due to the rarity of PNH in childhood it is difficult to estimate the exact incidence in affected pediatric populations, with estimates ranging from as low as 5 to $50 \% .^{14}$

We describe a case of a girl with a severe thrombotic complication of the disease.

\section{Case Report}

M. is a 14 year-old female, born fullterm to unrelated healthy parents after an uneventful pregnancy. Her parents reported regular growth and denied any clinical problems during the childhood. In February 2014 an unexpected finding of slight macrocytic anemia, leucopenia and mild thrombocytopenia (hemoglobin [Hb] 10.6 $\mathrm{g} / \mathrm{dL}$, mean corpuscular value $100 \mathrm{fL}$, iron $81 \mu \mathrm{g} / \mathrm{dL}$, ferritin $14 \mu \mathrm{g} / \mathrm{L}$, white blood cell [WBC] count $3.8 \times 10^{9} / \mathrm{L}$, neutrophils $2.6 \times 10^{9} / \mathrm{L}$, platelets $62 \times 10^{9} / \mathrm{L}$ ) was identified at routine blood analysis requested of the pediatrician in response to paleness in the child. A carential anemia due to menarche was diagnosed and iron, vitamin $\mathrm{B} 12$ and folic acid commenced. After three months of iron and folic therapy there was no improvement, but rather a worsening in the blood count. In June 2014, after a febrile episode, a blood count was
Correspondence: Francesco Gervasi, U.O. Laboratorio Specialistico di Oncologia, A.R.N.A.S. Civico, Di Cristina e Benfratelli, Piazza N. Leotta 490127 Palermo, Italy. Tel.: +39.091.6664346 - Fax: +39.091.6664352. E-mail: francesco.gervasi@arnascivico.it

Key words: Case report; Hemoglobinuria; Thrombosis; Fatigue; Eculizumab.

Acknowledgement: we thank Ray Hill, an independent medical writer, who provided English language editing assistance and medical writing support on behalf of Health Publishing \& Services Srl. The editorial support was funded by Alexion. No other funding was received for this report. The Parents' Association Sicilian Primary Immunodeficiency Association is acknowledged for supporting the activity of the Pediatric Onco-Hematology Unit of A.R.N.A.S. Ospedali Civico, Di Cristina e Benfratelli. No specific funding was received for this study.

Contributions: the authors contributed equally.

Conflict of interest: the authors declare no potential conflict of interest.

Conference presentation: Presented in part as an abstract at the XL Congresso Nazionale AIEOP, Lecce, Italy, May 2015. Abstract P078, Emoglobinuria parossistica notturna in età pediatrica: evenienza rara ma può essere importante pensarci.

Received for publication: 22 December 2016. Revision received: 22 February 2017.

Accepted for publication: 28 February 2017.

This work is licensed under a Creative Commons Attribution-NonCommercial 4.0 International License (CC BY-NC 4.0).

(C) Copyright F. Gervasi et al., 2017

Licensee PAGEPress, Italy

Hematology Reports 2017; 9:7012

doi:10.4081/hr.2017.7012

performed which continued to show thrombocytopenia (platelets $101 \times 10^{9} / \mathrm{L}$ ) and a worsened anemia ( $\mathrm{Hb} 8.4 \mathrm{~g} / \mathrm{dL}$ ), WBC $3.8 \times 10^{9} / \mathrm{L}$, neutrophils $1.3 \times 10^{9} / \mathrm{L}$.

In August 2014 the girl was referred to a children's hospital after the onset of progressive fatigue, associated with anorexia and paleness. The patient underwent blood routine biochemistry and a complete blood cell count. Laboratory findings showed severe anemia $(6 \mathrm{~g} / \mathrm{dL})$ with negative Coombs test, mild leucopenia (WBC $4.9 \times 10^{9} / \mathrm{L}$ ) and thrombocytopenia (platelets $97 \times 10^{9} / \mathrm{L}$ ) and high values of lactate dehydrogenase (LDH, $2855 \mathrm{IU} / \mathrm{L}$ ).

During the hospitalization the girl was 
subjected to a packed red cells transfusion, and to a further diagnostic work-up which included: bone-marrow analysis (which showed a normal cellularity without abnormal cells), autoimmunity antibodies complete panel, vitamin B12 and folate, urine analysis, tumoral markers $(\alpha-$ fetoprotein, CA 19-9, carcinoembryonic antigen [CEA], vanillylmandelic acid [VMA], neuron-specific enolase [NSE]), abdominal ultrasound, chest X-ray and total body computed tomography (CT). Clinical, laboratory and instrumental findings were all unremarkable, with the exception of sporadic hemoglobinuria, increase in reticulocyte count $(178,145 / \mu \mathrm{L})$ and persistently elevated levels of $\mathrm{LDH}$, with no other sign of hemolysis. The girl was therefore discharged. On 9 September, in response to the worsening of symptoms and the onset of pallor, the pediatrician ordered blood tests that showed a severe anemia ( $\mathrm{Hb} \quad 6.8 \mathrm{~g} / \mathrm{dL}$ ) and thrombocytopenia (platelets $112 \times 10^{9} / \mathrm{L}$ ) and high LDH serum levels $(3550 \mathrm{IU} / \mathrm{L})$. The patient was hospitalized, transfusions were started immediately and transfer to the Pediatric Hospital was decided upon.

During hospitalization, Coombs test was negative, total bilirubin $1.4 \mathrm{mg} / \mathrm{dL}$, direct bilirubin $0.4 \mathrm{mg} / \mathrm{dL}$, haptoglobin 8 $\mathrm{mg} / \mathrm{dL}$, autoimmunity negative, vitamin B12 and folates normal. A urine test showed traces of hemoglobinuria. The patient underwent bone marrow biopsy that showed an absence of aberrant phenotypes, depletion of CD34 ${ }^{+}$stem cells, lymphocytic depletion of B cells, and absence of B cell lymphoid progenitors. Throughout this time, LDH was always $>1.5 \times$ upper limit of normal (ULN; 11 September: 1283 IU/L; 12 September: 1469 IU/L; 15 September: 1436 $\mathrm{IU} / \mathrm{L})$.

The patient was discharged in good condition and did not report significant disorders. Laboratory findings at discharge were: $\mathrm{Hb} 11.1 \mathrm{~g} / \mathrm{L}, \mathrm{WBC} 3.4 \times 10^{9} / \mathrm{L}$, platelets $119 \times 10^{9} / \mathrm{L}$, and LDH $1210 \mathrm{IU} / \mathrm{L}$.

During school hours on 17 October, before any further examination could be performed, the patient presented an episode of loss of consciousness preceded by general discomfort, fatigue, blurred vision, vomiting, mental disorientation and speech difficulties. On arrival at the emergency area, the girl presented complete right hemiplegia, aphasia and underwent a deterioration of mental status leading to coma (GCS 7/15). Magnetic resonance imaging (MRI) and MR angiography (MRA) of the brain were performed immediately; MRI revealed a massive ischemic lesion of the territory fed by the middle cerebral artery in relation to a thrombotic event that had occurred both in this vessel and in the left median cerebral artery and MRA showed a significant flow reduction of left intracranial portion of the internal carotid artery and complete absence of ipsilateral middle cerebral artery flow (Figure 1).

Right hemiplegic pyramidal syndrome with cranial-caudal decreasing gradient and motorial aphasia with residual understanding of simple orders was apparent. Right positive Babinski sign was present. Laboratory finding were: $\mathrm{Hb} 10.0$ g/dL; WBC $2.6 \times 10^{9} / \mathrm{L}$, platelets $95 \times 10^{9} / \mathrm{L}$, LDH 1630 IU/L. After a brief period (24 hours) of hospitalization at the emergency department, during which intravenous low molecular weight heparin at 100 units $/ \mathrm{kg}$ was started, the girl was transferred to pediatric neuropsychiatry where she rapidly recovered from aphasia and the hemiplegic syndrome. After consulting the pediatric onco-hematologist, a hemoglobin study using high-performance liquid chromatography (HPLC), osmotic resistance and ADAM metallopeptidase with thrombospondin type 1 motif 13 (ADAMTS 13) and related antibodies were performed trying to find the pathogenesis of the cerebral thrombosis: all of them were normal.

According to the International Clinical Cytometry Society (ICCS) 2010 guidelines, ${ }^{15}$ all patients with cytopenia associated with hemolysis and/or thrombosis should be studied for $\mathrm{PNH}$. Therefore we performed high sensitivity flow cytometry on flow cytometer Navios $^{\mathrm{TM}}$ (Beckman Coulter, Ca, USA) and the presence of a PNH clone was shown: CD66b negative equal to $93.7 \%$ of granulocytes, CD14 negative equal to 95.2\% of monocytes and CD59 negative equal to $1.5 \%$ of the erythrocytes. The bone marrow biopsy documented erythroid hyperplasia and left shift of the line myeloid maturation. The girl was initially managed with low molecular weight heparin, steroids, vitamin B12 and folic acid, after that, in November, an oral anticoagulant (warfarin) and intravenous therapy with the humanized monoclonal antibody eculizumab were started with good results (no further transfusions were needed). Concomitant treatment with warfarin was continued. In July 2015 a follow up MRI

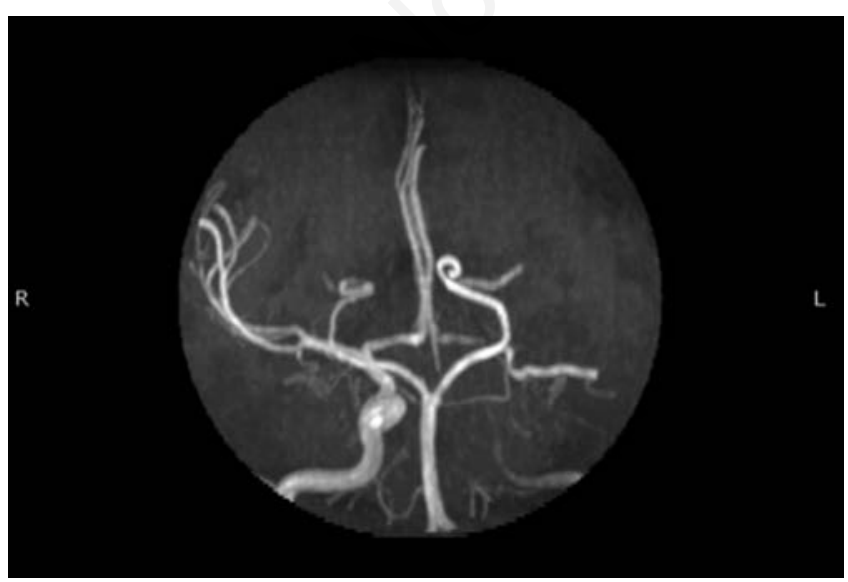

Figure 1. Magnetic resonance angiography showing a significant flow reduction of left intracranial portion of the internal carotid artery and complete absence of ipsilateral middle cerebral artery flow.

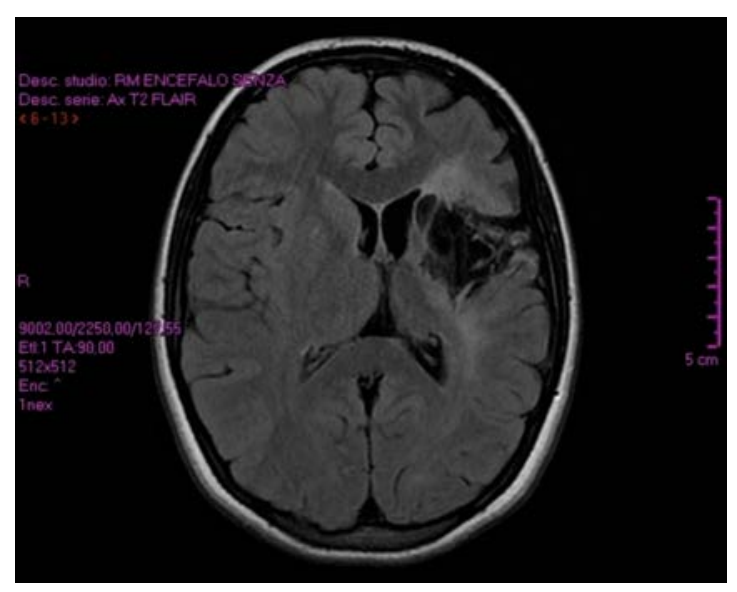

Figure 2. FLAIR magnetic resonance imaging showing a gliotic and poroencephalic outcome of the previous ischemic lesion in left cortical-subcortical fronto-temporal region, with ex-vacuo dilatation of ipsilateral ventriculum. 
revealed a gliotic and poroencephalic outcome of the previous ischemic lesion in left cortical-subcortical fronto-temporal region, with ex-vacuo dilatation of the ipsilateral ventriculum (Figure 2). At follow up in March 2016 aphasia was almost regressed and gait normalized. Motility was recovered in the right upper limb, but was still absent at the level of the wrist and right hand. The patient had not required further transfusion. Hematological samples withdrawn just before the infusion with eculizumab showed average values of $\mathrm{Hb}$ 8.9-9.4 g/dL, platelets $120-140 \times 10^{9} / \mathrm{L}$, reticulocytes $170-310,000 / \mathrm{mL}$, LDH 700 $1,100 \mathrm{IU} / \mathrm{L}$, total bilirubin 1.2-1.6 mg/dL.

Written informed consent was obtained from the parents of the patient for publication of this case report and the accompanying images. Approval from the hospital's ethics committee was not applicable, as this was an individual clinical case.

\section{Discussion}

Though arterial occlusion is a less frequent complication in paroxysmal nocturnal hemoglobinuria, accounting for about $15 \%$ of total thromboembolism events in adults, cerebrovascular complications such as stroke or transient ischemic attack represent almost $90 \%$ of arterial thrombotic events in this condition. ${ }^{16}$ Audebert et al. reported two cases of cerebral ischemic infarction, one of which was a 16-year old girl with known PNH and aplastic anemia, and reviewed 7 previously reported cases in the literature, one on a 11-year old girl with pancytopenia, obtaining follow-up information on 4 of the 5 patients who survived. ${ }^{17}$ Both of the two cases had experienced hemoglobinuria and cytopenia prior to the thrombotic events, and in one case diagnosis of PNH was only established after stroke onset. The review of the other 7 cases showed that two patients died during their in-hospital treatment or during a short period after discharge. Out of the nine patients, four died within a few weeks after the initial thrombotic event, and five had the arterial thrombosis as one of the first manifestations of PNH and the underlying disease was diagnosed later during the clinical course. ${ }^{17}$ It appears that in the case of thrombotic complications both the prompt administration of eculizumab and thrombolytic therapy, above all with administration of intravenous tissue plasminogen activator, may be decisive in improving outcome. ${ }^{18}$ In children, typical $\mathrm{PNH}$ is rare, manifests mostly in teenage years and the incidence of thrombosis has an average of $23 \%$, ranging up to $50 \% .{ }^{14}$ Due to the disease rarity the diagnosis is, as in our case, often delayed. ${ }^{8-12,17}$ In our patient eculizumab was not started immediately after cerebral stroke (the correct diagnosis was not made until a few days later) whereas thrombolytic therapy was not performed by decision of the emergency physicians, since the girl showed a rapid recovery of general conditions. In fact, in the event of an earlier diagnosis we would have immediately started therapy with eculizumab and warfarin and the girl would likely not have suffered thrombotic complications.

\section{Conclusions}

In conclusion, we think that in the presence of cytopenia, regardless of type, a child should immediately be referred to a pediatric onco-hematology unit and that in the case of an association with hemolytic signs, if the most common diseases (i.e. autoimmune hemolytic anemia) have been excluded, the child should be immediately evaluated for a PNH clone. This approach, making use of a simple and low-cost test, could ensure appropriate management of the condition and avoid the likelihood of a severe and potentially fatal outcome, linked to the elevated risk in PNH patients of both venous and arterial thrombosis.

\section{References}

1. Takeda J, Miyata T, Kawagoe K, et al. Deficiency of the GPI anchor caused by a somatic mutation of the PIG-A gene in paroxysmal nocturnal hemoglobinuria. Cell 1993;73:703-11.

2. Miyata T, Takeda J, Iida Y, et al. The cloning of PIG-A, a component in the early step of GPI-anchor biosynthesis. Science 1993;259:1318-20.

3. Miyata $T$, Yamada N, Iida $Y$, et al. Abnormalities of PIG-A transcripts in granulocytes from patients with paroxysmal nocturnal hemoglobinuria. N Engl J Med 1994;330:249-55.

4. Bessler M, Mason PJ, Hillmen P, et al. Paroxysmal nocturnal haemoglobinuria (PNH) is caused by somatic mutations in the PIG-A gene. EMBO J 1994;13:110-7.

5. Medof ME, Kinoshita T, Nussenzweig V. Inhibition of complement activation on the surface of cells after incorporation of decayaccelerating factor (DAF) into their membranes. J Exp Med 1984; 160:1558-78.

6. Rollins SA, Sims PJ. The complementinhibitory activity of CD59 resides in its capacity to block incorporation of $\mathrm{C} 9$ into membrane C5b-9. J Immunol 1990;
144:3478-83.

7. Rother RP, Bell L, Hillmen P, Gladwin MT. The clinical sequelae of intravascular hemolysis and extracellular plasma hemoglobin: a novel mechanism of human disease. JAMA 2005;293:1653-62.

8. Ware RE, Hall SE, Rosse WF. Paroxysmal nocturnal hemoglobinuria with onset in childhood and adolescence. N Engl J Med 1991;325:991-6.

9. Naithani R, Mahapatra M, Dutta P, et al. Paroxysmal nocturnal hemoglobinuria in childhood and adolescence. A retrospective analysis of 18 cases. Ind J Pediatr 2008;75:575-8.

10. Curran KJ, Kernan NA, Prockop SE, et al. Paroxysmal nocturnal hemoglobinuria in pediatric patients. Pediatr. Blood Cancer 2012;59:525-9.

11. van den Heuvel-Eibrink MM, Bredius RG, te Winkel ML, et al. Childhood paroxysmal nocturnal haemoglobinuria (PNH), a report of 11 cases in the Netherlands. Br J Haematol 2005;128: 571-7.

12. Urbano-Ispizua A, Schrezenmeier $H$, Muus $\mathrm{P}$, et al. Clinical characteristics of classic paroxysmal nocturnal hemoglobinuria (PNH) in pediatric patients: A comparison with classic $\mathrm{PNH}$ in adults. An International PNH registry study. Blood 2011;118:2102.

13. Hill A, Kelly RJ, Hillmen P. Thrombosis in paroxysmal nocturnal hemoglobinuria. Blood 2013;121:4985-96.

14. Urbano-Ispizua A, Muus P, Schrezenmeier H, et al. Different clinical characteristics of paroxysmal nocturnal hemoglobinuria in pediatric and adult patients. Haematologica 2017;102:e76-9.

15. Borowitz MJ, Craig FE, Digiuseppe JA, et al. Guidelines for the diagnosis and monitoring of paroxysmal nocturnal hemoglobinuria and related disorders by flow cytometry. Cytometry B Clin Cytom 2010;78:211-30.

16. Hillmen P, Muus P, Dührsen U, et al. Effect of the complement inhibitor eculizumab on thromboembolism in patients with paroxysmal nocturnal hemoglobinuria. Blood 2007;110:4123-8.

17. Audebert HJ, Planck J, Eisenburg M, et al. Cerebral ischemic infarction in paroxysmal nocturnal hemoglobinuria report of 2 cases and updated review of 7 previously published patients. J Neurol 2005;252: 1379-86.

18. Araten DJ, Notaro R, Thaler HT, et al. Thrombolytic therapy is effective in paroxysmal nocturnal hemoglobinuria: a series of nine patients and a review of the literature. Haematologica 2012;97:34452. 